\title{
INNOVATION MANAGEMENT: A NEW SERIOUS GAME ALIGNED WITH ISO 56002:2019 - INNOVATION MANAGEMENT SYSTEM
}

\author{
Laure MOREL ${ }^{1}$ and Johan CLAIRE ${ }^{2}$ \\ ${ }^{1}$ Université de Lorraine - ERPI, F-54000 Nancy, France \\ ${ }^{2}$ Innovation Way
}

\begin{abstract}
Innovation and Innovation Management are now common topics in the education field. However, the majority of the contents take the form of basic media: books, articles, courses, study cases and they are also taught in a linear way: lectures, tutorials. This does not consider new trends in terms of teaching, such as reverse pedagogy or pedagogy through games and does not seem appropriate when dealing with the teaching of complex topics such as innovation. The purpose of this article is therefore to present a new serious game which aim is to help students from engineering school, business school or master degree in innovation to acquire basic knowledge on building and assessing innovation management system using a playful way. The plus of the game: it is aligned with the standard ISO 56002: 2019 Innovation Management System [1]. In this paper, we will explain the methodological approach we used to design the game and in conclusion we will present some results issued from two experimentations we already have.
\end{abstract}

Keywords: Innovation Management System, innovation, engineering education, Serious Game, ISO 56002

\section{INTRODUCTION}

Innovation and Innovation Management are now an integral part of the entrepreneurial discourse. Training students in these fields has therefore become a must. However, it must be said that the desires and expectations of new generations of students in terms of training have changed: they are in demand for more flexible, more collaborative teaching methods in place of the traditional lectures, supervised work and practical work. They are asking us, as trainers, to be creative and innovative in order to capture their attention. The challenge is therefore to succeed in creating something that can both increase their competence in the field of creativity and management of innovation while meeting these new needs for less intrusive pedagogy.

In this article, we have chosen not to dwell on the justification of the relevance of using a serious game to teach innovation. Authors such as [2] have demonstrated this perfectly. Serious game approach makes it possible to acquire knowledge more easily compared to traditional training through engagement and motivation [3][4]. The main purpose of this article is to present a new educational game dedicated to student taking courses in innovation engineering or innovation management. Section 2 introduces the context of our work, the recent ISO standard in Innovation Management System that give new definition and directions to follow. Section 3 describes our methodological approach to design our serious game. Section 4 shows the visuals associated. A short discussion and perspectives are proposed in the concluding section.

\section{ISO STANDARD IN INNOVATION MANAGEMENT SYSTEM FRAMEWORK}

ISO Technical Committee on Innovation Management (ISO TC 279) was been created in 2013. It aims to describe terminology, tools and methods, and interactions between relevant parties to enable innovation within organizations. Published in July 2019, the ISO 56002:2019 - Innovation Management System standard aims to provide a framework to develop innovation management capabilities. This standard describes a set of processes by which an organization manages a set of activities to achieve its innovation objective. All Management System Standards are based on a common framework used to 
describe management systems in general. It sets a table of content to follow and provide recommendations regarding the process of writing. It is clear that seeking to standardize innovation management may seem contradictory. This is why it is important to note that this standard is a guidance standard and not a requirement standard. It therefore aims to highlight good practices for steering innovation processes, commonly accepted by a pool of international experts.

We assume that training students in innovation cannot be done without taking as a reference this standard, which contains both definitions and explanations on how to steer an innovation process by considering the ecosystem in which it evolves.

Consequently, we will use the following definition provided by ISO 56000:2020 [5]:

- Innovation is "a new or changed entity, realizing or redistributing value" where:

○ Entity can refer to a product, service, process, model, or method;

- Value can be financial or non-financial (for example image, strategic advantage, knowledge acquisition, intellectual property); and

- Novelty (newness) and value are relative to, and determined by, the perception of the organization and interested parties.

- An Innovation Management System (IMS) includes all elements and their interactions that are needed for an organization to establish its innovation capabilities for the purpose of effectively and sustainably achieving innovations.

The IMS coordinates and directs the organization's innovation activities to ensure alignment to their customer and business requirements. It also provides mechanisms to measure and improve innovation effectiveness and efficiency on a continuous basis.

The objective of considering a systemic approach here is to move away from a vision exclusively centred on the development of an innovative project process (operational vision) by positioning innovation project processes within a broader organisational system.

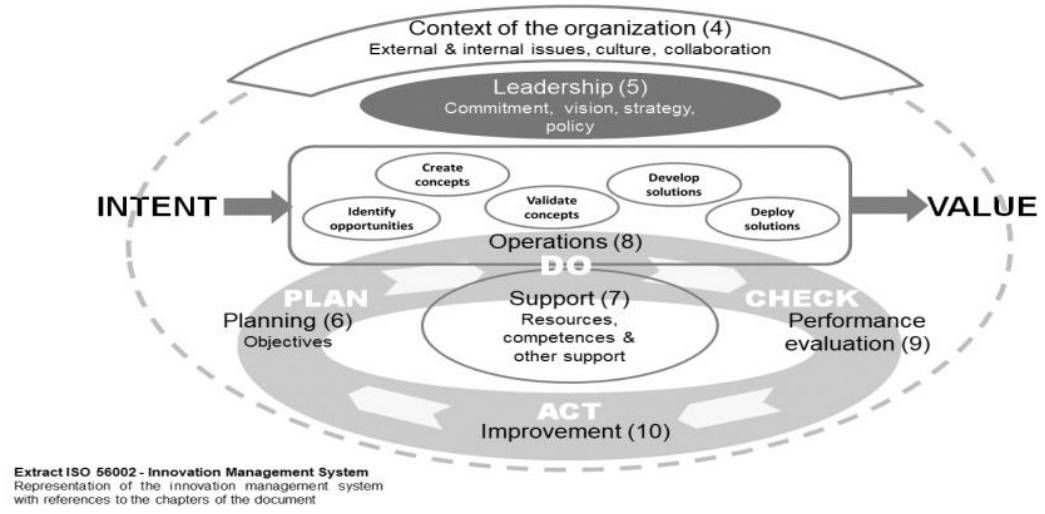

Figure 1. Innovation management system representation. Source: Extract ISO 56002

As any management system, the IMS can be continuously improved by using and Plan-Do-Check-Act (PDCA) approach.

As shown in Figure 1, the standard is a dense document, organised in 10 chapters containing definitions, methods and tools that any manager working in or wanting to work in the field of innovation should be familiar with. Nevertheless, the style of language and the imposed structure of the document do not make it easy to read and understand, especially for students.

As an expert from the French delegation, who participated in the drafting of the standard, we felt it would be appropriate to try to translate it into simpler terms and in a more entertaining format in order to attract more students to this subject.

Thus, for the construction of our game, we adopted the definitions and general framework of ISO 56002 (chapters 1 to 3 of the standard) as well as the model presented in figure 1 to formalize an innovation management system (chapters 4 to 10 of the standard).

\section{METHODOLOGICAL APPROACH TO DESIGN THE SERIOUS GAME}

The objective of the game is to give concrete expression to the notion of an Innovation Management System, to materialize the dynamics of such a system and to reveal the importance to balance idea generation, project development capabilities, value generation and resilience. 
Serious games in general are created to train people in a more fun approach than classical training. They make it easier for users to get involved and to master the principles taught in the training materials more quickly [6]. However, the creation of serious games requires a greater effort than the construction of a classical training [7].

This is why we have chosen, for this article, to focus on the construction logic that was ours.

As stated by [8], the main purpose to create simulation games is to concentrate all the educational objectives that a teacher may seek, namely knowledge, understanding, application, analysis, synthesis and evaluation. Furthermore, as pointed out by [6], many factors need to be considered when developing the elements of the game, such as the complexity of the subject, the history of the game, the mechanics of evolution and the challenges to be faced. [2] have also tested a 6 items framework called SGDA (Serious Game Design Assessment, designed by [9] to help teacher or trainer in innovation to transform their traditional supports onto innovative ones, such as serious game. The 6 items are: Game purpose, Content \& Information, Mechanics, Fiction \& Narrative, Aesthetics \& Graphics and Framing.

On the basis of these works, we have developed a specific approach for our complex subject: training students at Master's degree level in innovation by advocating a system vision of innovation aligned with the content of standard 56002. The result is a 4-step approach as follows:

- $\quad$ Step 1: Complexity and game purpose (objectives and Knowledge)

- $\quad$ Step 2: Content, Mechanics \& and associated framing

- $\quad$ Step 3: Test, learn and adapt to better fit reality.

- $\quad$ Step 4: Aesthetics \& Graphics

\subsection{Step 1: Complexity and game purpose (objectives and Knowledge)}

Objectives: Clearly define the objectives of the game and the challenges to be faced in order to reduce the complexity of the subject. Explain also the history of the game.

The development of this game stems from our experience as experts in drafting the Innovation Management Standards series. Innovation is an eminently complex process that takes different forms depending on whether you want to manage, steer or evaluate it. ISO 56002:2019 lays the foundations for understanding what an innovation process is and the ecosystem in which it evolves.

The use of an accessible vocabulary to link multiple notions related to the field of innovation was a major challenge for us. Indeed, concerning the knowledge gained from the game, we wanted students to:

- make the link between the implementation of activities in a company (system) and the impact on the flow of innovation (projects),

- Integrate the importance and the complexity to balance an innovation portfolio under development and to regularly produce innovation,

- Understand the value acquisition process and the fragility of an innovation under development.

\subsection{Step 2: Content, Mechanics \& and associated framing}

Objectives: Select the content you want to reflect. Define the mechanics of the game and all the aspects related to the gaming process: time, period, cycle, ...

In order to adhere as closely as possible to the standard in terms of content: definitions, methods and referenced tools, we have carried out two actions:

- "decoding" the standard, i.e. we translated the various paragraphs into the form of simple activity cards using business vocabulary. We defined 4 categories of cards associated with specific chapters of ISO 56002:2019:

- Strategy cards are related to chapters 4 Context of the Organisation, 5 Leadership and 6 Planning),

- Support cards describe activities related to chapter 7: Supports,

- Project management cards describe activities related to chapter 8 Operations,

- Continuous improvement card is related to chapter 9 Evaluation and 10 Improvement.

- Define game mechanics rules that would illustrate the principles of IMS development described in the standard:

- each activity should have an impact on the system performance,

- the system should be built over time and provide a level of efficiency corelated to the implemented activities,

○ the objective of the game would be to accumulate value by realizing innovations. 
ISO 56002 precise that the elements of the system can be gradually adopted, according to the particular context and circumstances of the organization and that full benefits can be gained when all the elements of the innovation management system, are adopted by the organization. Thus, the order of implementation of the different innovation activities can vary. This is why we proposed a dynamic approach, non-linear, where player will be free to choose the order of implementation.

The game will be played over a 12-month period with each month representing a round. This will position us in a realistic framework where activities take time to be implemented and where the system will be monitored over a year. It is therefore a question of implementing the activities in the system, and allocating the resources and means to achieve this.

Considering that the objective of an IMS is to generate value, we have opted for a game by accumulation of resources. Player will make visible material gains in the form of multi-coloured diamonds that will illustrate the multiple forms that value may take.

At this stage of our work, we have a deck of cards representing innovation activities, some focusing on managing innovative projects and some others focusing on the ecosystem aspect in which a project evolves. We also have a currency (diamonds) as a resource and a correspondence between game rounds and time (1 game round representing 1 month, game round over a year).

An initial validation by a first expert committee was carried out. The committee was mainly composed of ISO TC 279 members. Although they appreciated the suggested contents and overall concept, they nevertheless raised the question of the impact of these activities on the performance of the system.

Working with the expert committee, we decided to:

- Define the variables to be retained as KPIs for the performance of the IMS, namely: ability to generate idea, ability to move projects forward, ability to generate value, and resilience of the organization,

- Define the impact of each activity (card) among the 4 defined KPIs,

- Differentiate two currencies or the game. In spite of the diamonds that will represent the value created threw innovation, we define another currency that will reflect the limited resources the player will have to implement innovation activities,

- Use the project process of the standard, and decide on the number of boxes a project will have to cross in each phase (e.g., it takes longer to do the development phase than to create a concept) and the potential value gain while progressing on the project process,

- Propose a calculation of the associated costs per activity (not all activities are so simple to deploy),

- $\quad$ Propose the calculation of a value/investment ratio revealing priority activities.

At the end of this stage, we have a first functional prototype of the game.

\subsection{Step 3: Test, learn and adapt to better fit reality}

Using the functional prototype, we realized a validation phase with a second experts committee mixing experts that were and were not directly linked to ISO TC 279.Their feedback noted that the game was very theoretical and lacked realism. Indeed, while developing innovation company has to face hazards, unforeseen events. Also, collaborating with external partners is also a common practice that we did not integrate in the game. We therefore introduced new cards, based on two principles:

- Illustration of the system agility: give an idea to the player of what and IMS can undergo and how it reacts. This will be illustrated by hazard cards that will be randomly drawn among the game,

- Consideration of using external resources to invite the player the ability to partner of specific projects. This will take the form of joker cards.

At the end of this stage, we have a complete game prototype, validated by the 2 experts committees.

\subsection{Step 4: Aesthetics \& Graphics}

Objectives: Try to find the most accurate visual for the game. It must help to understand the all-purpose of the game in one look, support the flow of the game and must not create a barrier for the intended users.

At this stage of our research and considering feedback from experts, our aim was to make the system visible to users. We worked with two designers who made us several proposals, in order to put the graphics at the service of the objective. Two aspects were researched:

- Define the graphic universe that is consistent with the theme of innovation and that can be compatible with all types of organisations (private company, public service, etc.), we particularly 
cared not to go towards an analogy to avoid cognitive dissonance,

- Integrate keys into the graphics and make sure that each element has sense (organization of the game board lengthwise for process projects, hide the difficulty of the development phase by presenting the pieces in columns, represent the diversity of people on the game board, represent a space for creativity, etc.). The aim is to initiate discussions and invite the player to interpret each graphic element of the game.

A third validation by an expert committee led to a warning: if the graphics accentuate comprehension but lead some of the testers to be too involved in the game and to stray from the desired learning experience. We will take this point into account in the future.

At the end of step 4, we have our final serious game, validated by the experts and with a visual done by a designer. Its presentation is the purpose of the next clause.

\section{OUR PROPOSAL: « L'ANNÉE DE L'INNOVATION ${ }^{\circledR}$ »}

The result of the approach previously presented lead to our serious game called "l'Année de l'Innovation ${ }^{\circledR}$ ". The game will be available in French, English and Spanish.

Let us present the visuals selected for the game and summarize the rules:

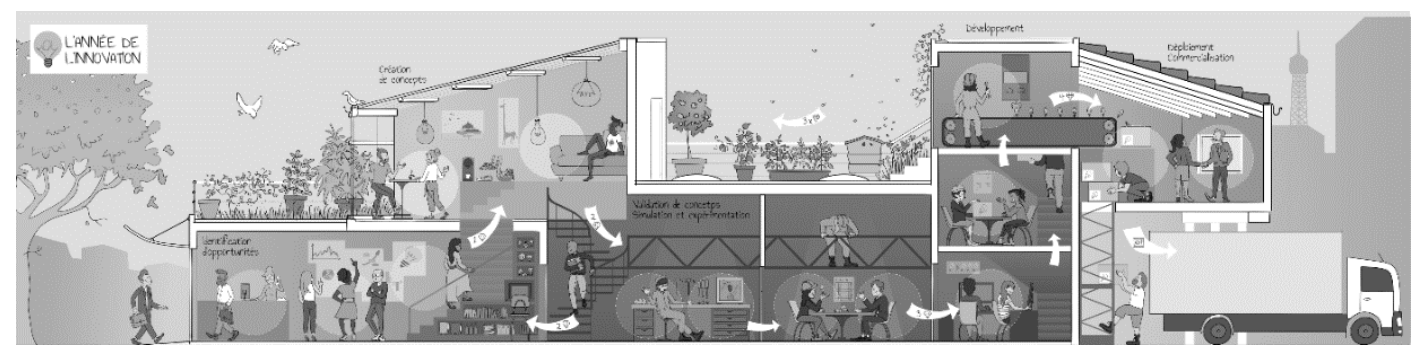

Figure 2. The game board that connects SMI with the development of innovative projects

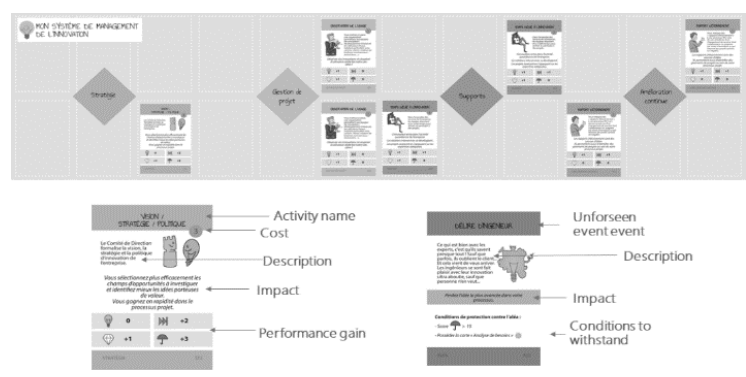

Figure 3. The tray and the cards simulating an IMS

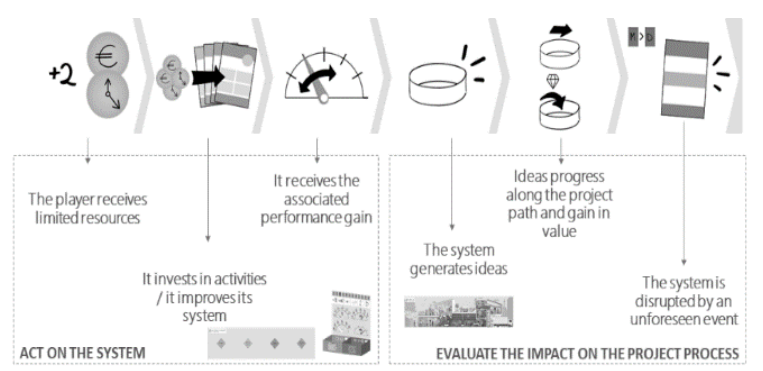

Figure 4. description of a game round

The serious game is the result of a co-design dynamic with industrial and academics. In order to validate is accuracy for training students, we tested our serious game with three types of students with different backgrounds and mindsets: entrepreneurship students, innovation management students and risk management students. The results obtained are interesting and will help to improve our serious game. This will be presented in a paper to come. 


\section{CONCLUSION AND PERSPECTIVES}

In this article, we present a new game that allows to train students in an active and creative way based on the new Iso Standard dedicated to Innovation Management. Reading a standard is not a common purpose for students. Furthermore, the content of a standard is more for an expert of the domain. So, it usually requires an adaptation step to understand it. We facilitated that step by declining all the ISO 56002 chapters into a serious game. Thanks to the three rounds validation, we can say that the game meets most of its expectations: the innovation management best practices were understood and the students asked to play again in order to try another strategy to better perform. We were also satisfied because the game let see some concrete managerial implication: to work as a team, to negotiate, argue and find a consensus when several scenarios appeared.

In the future, a more normative evaluation of the learning process will be necessary and can be carried out in order to measure the efficiency of the serious game [10]. This evaluation will show which type of audience is the most receptive and which requires an adaptation of the game [8]. Consequently, we have already planned two new sessions with students coming from an engineering school and a business school.

\section{REFERENCES}

[1] ISO 56002 Standards. Innovation management - Innovation management system - Guidance, 2019 (International Organisation for Standardization (ISO) Editions).

[2] Ma Y., Vallet F., Cluzel F. and Yannou B. Analysing the Relevance of Serious Game Elements for Effectively Teaching Innovation Processes. In International Conference on Engineering Design, ICED'19, Vol. 1, Delft, August 2019, pp.439-448 (Professional Engineering Publishing, Bury St Edmunds).

[3] Avila-Pesantez D., Delgadillo R. and Rivera L. A. Proposal of a Conceptual Model for Serious Games Design: A Case Study in Children with Learning Disabilities. In IEEE Access 7, 2019, Vol. 7, pp161017-161033.

[4] Carrion M., Santorum M., Harold F., Aguilar J. and Perez M. Serious game, gamified applications, educational software: A comparative study. In International Conference on Information Systems and Software Technologies, ICI2ST 2019, 2019, pp55-62.

[5] ISO 56000 Standards. Innovation management - Fundamentals and vocabulary, 2020 (International Organisation for Standardization (ISO) Editions).

[6] Mahmoud M. and Faragallah O. S. Development of Serious Games for Teaching Information Security Courses. In IEEE Access 7, 2019, pp169293-305.

[7] Wilson D. W., Jenkins J., Twyman N., Jensen M., Valacich J., Dunbar N. and Wilson S. Serious games: An evaluation framework and case study. In Annual Hawaii International Conference on System Sciences, Hawai, March 2016, pp.638-47.

[8] Frutuoso Silva. G. M. Practical methodology for the design of educational serious games. Information, 2020, 11 (1), 1-13.

[9] Mitgutsch K. and Alvarado N. Purposeful by design: a serious game design assessment framework. In International Conference on the foundations of digital games, 2012, pp.121-128.

[10] Tubelo R. A., Portella F. F., Gelain M. A., de Oliveira M. M. C., de Oliveira A. E. F., Dahmer A., and Bresolin Pinto M. E. Serious game is an effective learning method for primary health care education of medical students: A randomized controlled trial. International Journal of Medical Informatics, 2019, Vol 130, pp.103944. 